\title{
EB virus in relation to tumours
}

\author{
B. G. ACHONG
}

From the Department of Pathology, University of Bristol

When Burkitt first described the lymphoma which now bears his name, the most striking aspect of the tumour was the apparent dependence of its distribution on climatic factors. That the incidence of the tumour could be influenced by temperature and rainfall suggested at once that some biological agent was concerned in its causation, and the decision to seek possible aetiological viruses in Burkitt tumour material led directly to the discovery of the EB virus in 1964 (Epstein, Achong, and Barr, 1964).

The EB virus was immediately recognized as belonging morphologically to the herpes group (Figs. 1-3), and subsequent serological, immunological, and biological tests have amply confirmed that this virus is indeed a new and distinct member of the herpes group of viruses (Epstein and Achong, 1970).

This review will cover the present status of the EB virus in relation to the tumours with which it has a marked association, namely, Burkitt's lymphoma and nasopharyngeal carcinoma, with special emphasis on its oncogenic potential. There are now well over 100 viruses which are known to cause virtually all kinds of cancer in every major group of animals including subhuman primates. The question naturally arises whether malignant tumours in man have a similar aetiology to the experimentally proven virus-induced neoplasms in animals or whether man is in some way unique in the animal kingdom and some special dispensation provides that no human malignant tumour should have a viral aetiology. If this latter proposition is deemed unwarrantable, then it becomes possible to speculate that some at least of human malignancies have a viral cause. Here, however, we come to a great impasse. In the case of animals, every example of an oncogenic virus has been demonstrated by the inoculation of the putative virus into animal hosts. In the case of man, this direct procedure being obviously impossible, indirect procedures have to be resorted to involving epidemiology, tissue culture, electron microscopy, cytology, serology, immunology, biochemistry, and inoculation into other species.

Let us consider what we know of the EB virus in the light of the four postulates proposed by Henle (1971), which a suspected human tumour virus must satisfy before it can be termed an oncogenic agent for man. These are.

\section{Presence of the Virus or Virus-determined Antigens or Viral Nucleic Acid in the Tumour}

PRESENCE OF EB VIRUS PARTICLES

EB virus particles have never been seen in tumour biopsies of Burkitt's lymphoma or nasopharyngeal carcinoma and in this respect EB virus resembles the DNA oncogenic viruses like polyoma, $\mathrm{SV}_{4} 0$, and adenovirus, and more relevantly it resembles two known oncogenic animal herpes viruses-the agent (MDHV) which causes Marek's disease in chickens (Churchill and Biggs, 1967) and Herpes saimiri which causes a rapidly fatal reticulum cell sarcoma in owl monkeys and marmosets (Meléndez, Hunt, Daniel, Garciá, and Fraser, 1969; Meléndez, Daniel, Hunt, Fraser, Garciá, King, and Williamson, 1970); virus particles are not seen in the tumours caused by any of these viruses. However, after a few weeks in culture Burkitt lymphoma cells regularly show the presence of EB virus particles and this is exactly what happens when the tumours induced by MDHV and $H$. saimiri are placed in culture, when their respective herpes aetiological agents appear as formed particles in the cultivated cells (Ahmed, Jensen, Slattery, Leech, and Schidlovsky, 1970; Rabson, O'Conor, Lorenz, Kirschstein, Legallais, and Tralka, 1971).

EB-VIRUS-DETERMINED ANTIGENS

\section{Intracellular immunofluorescence}

The original Henle indirect immunofluorescence test (Henle and Henle, 1966) detects viral capsid antigen and this appears relatively late during the viral cycle. Early antigen is another EB virus-associated intracellular antigen discovered by the Henles (Henle, Henle, Zajac, Pearson, Waubke, and Scriba, 1970). While viral capsid antigen represents a late viral product, early antigen occurs early in the viral cycle and is independent of viral DNA synthesis. Burkitt lymphoma biopsy cells do not show the presence of viral capsid or early antigens but when 


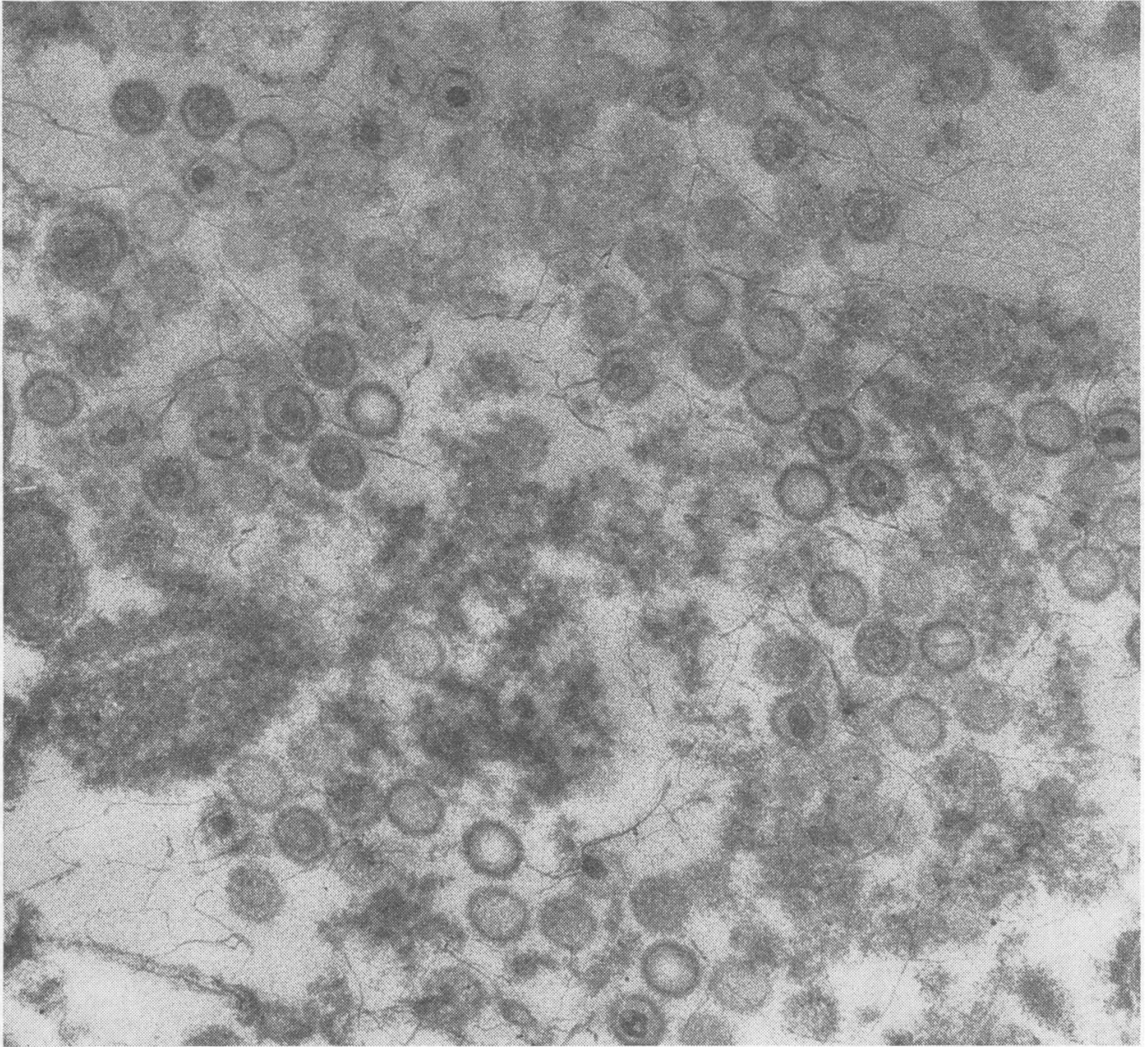

All the

illustrations

are electron

micrographs

of thin

sections of

cultured

Burkitt

lymphoblasts

fixed in

glutaral-

dehyde

followed by

osmium,

embedded in

epoxy resin,

and contrast

stained in the

section with

uranyl

acetate.

Fig. 1.

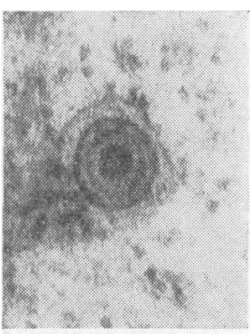

Fig. 2.

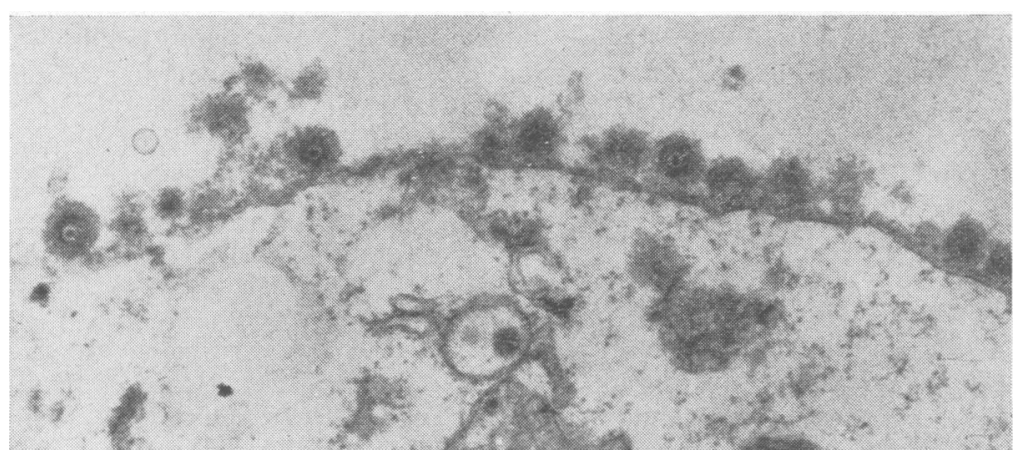

Fig. 3.

Fig. 1 Portion of an EB3 lymphoblast showing numerous immature EB virus particles. These measure 75 to $80 \mathrm{m \mu}$ in diameter and are either empty or contain ring-shaped or dense central nucleoids $(\times 72000)$.

Fig. 2 Detail of an EB3 lymphoblast showing a mature EB virus particle, $115 \mathrm{m \mu}$ in diameter and with its additional enveloping membrane, lying within a cytoplasmic space. The dense central nucleoid measures about $45 \mathrm{m \mu}$ across $(\times 102000)$.

Fig. 3 Detail of the surface of an EB1 lymphoblast with several mature EB virus particles lying in the extracellular space close to the plasmalemma which crosses the field horizontally $(\times 30000)$. 
placed in culture viral capsid antigen and/or early antigen develop in up to $5 \%$ of the cultivated cells within three to five days (Nadkarni, Nadkarni, Klein, Henle, Henle, and Clifford, 1970). It has been suggested that early antigen is analogous to the $T$ antigens found in all cells transformed by oncogenic DNA viruses. Like early antigen, $T$ antigens are intracellular antigens which are early components of the viral cycle and are independent of viral DNA synthesis.

\section{Membrane immunofluorescence}

It is clear from the extensive work of the Kleins and their collaborators (Klein, Clifford, Klein, and Stjernswärd, 1966; Klein, Klein, and Clifford, 1967) that EB virus also determines the production of a non-virion but virus-mediated neo-antigen on the surface of Burkitt lymphoma cells. Although viral capsid and early antigen are suppressed in vivo, the EB-virusdetermined membrane antigen of the Kleins is present in Burkitt lymphoma biopsy cells as well as in derived cell lines. Membrane antigen appears to be quite distinct from the intracellular early and viral capsid antigens, but like early antigen, it is produced early in the viral cycle and is independent of viral DNA synthesis. Non-oncogenic viruses do not have the capacity to induce neoantigens on plasma membranes and it is possible that membrane antigen is analogous to the viral-induced transplantation-type membrane antigen shown by all virus-induced animal tumours.

\section{Complement-fixation antigens}

The complement-fixing antigens present in EB viruscarrying cell lines have been divided by Walters and Pope (1971) into three components. One was a heat-resistant, sedimentable virion component, a second was a heat-labile sedimentable component, and the third was a heat-resistant soluble component. The soluble CF antigen (S) is EB virus-associated and is distinct from viral capsid, early, and membrane antigens. The $\mathbf{S}$ antigen was present in the Raji Burkitt lymphoma cell line and three lymphoblastoid cell lines derived from heatlhy donors. These four cell lines were negative for EB virus by electron microscopy and by the Henles' immunofluorescence test, and here it was shown that apparently EB virusfree lymphoblastoid cell lines were actually carrying the EB virus genome. It has been suggested that the $S$ antigen is a non-structural protein coded by the EB virus genome and, like early antigen, it resembles the $T$ antigens in the experimental oncogenic DNA virus systems.

\section{Immunoprecipitation}

Using Ouchterlony immunodiffusion techniques, Old, Boyse, Oettgen, de Harven, Geering,
Williamson, and Clifford (1966) detected a soluble antigen present in cultured EB virus-carrying Burkitt lymphoma cells. This was also the first time that a serological similarity between Burkitt lymphoma and nasopharyngeal carcinoma was demonstrated. This antigen is not the same as early antigen although both represent intracellular and probably non-structural early proteins, but it may correspond to the complement-fixing (S) antigen.

PRESENCE OF EB VIRAL NUCLEIC ACID

Cloning experiments have shown that every cultured Burkitt lymphoma cell probably contains the EB viral genome. Zajac and Kohn (1970), using the EB2 strain of Burkitt lymphoma cells which showed EB virus-specific immunofluorescence in $0.1-1 \%$ of cells, obtained clones from singly seeded EB2 cells in the presence of EB virus antibodies, and all the 23 established sublines resembled the parent culture in the incidence of EB virus antigen-containing cells.

However, the final confirmation of the extremely close association of EB virus with Burkitt's lymphoma, nasopharyngeal carcinoma, and seemingly virus-free lymphoblastoid cell lines was established by Zur Hausen. The most characteristic feature of virustransformed cells is the presence of virus-specific nucleic acid within every tumour cell. In the case of the DNA oncogenic viruses the presence of viral nucleic acid in the transformed cell has been demonstrated by hybridization techniques. Therefore, if EB virus is indeed an oncogenic DNA virus it would be expected that its nucleic acid should be present in every tumour cell and every cell of a transformed lymphoblastoid established cell line. By means of DNA/DNA hybridization experiments Zur Hausen and Schulte-Holthausen (1970) first showed the presence of six EB viral genomes in each Raji cell, the Raji cell line being a Burkitt lymphoma line which up to that time had never shown the presence of EB virus either directly in the electron microscope or immunologically using the Henles' and the Kleins' immunofluorescence tests; Pope, Horne, and Wetters (1969) had, however, reported that the Raji line did contain the EB virus-associated complement-fixing (S) antigen. Using the more sensitive technique of complementary RNA-DNA hybridization, Zur Hausen has now promoted the Raji line from the approximate number of six genome equivalents per cell to 40-55 (Zur Hausen and Schulte-Holthausen, 1971). They also showed the presence of EB viral DNA in eight 'virus-free' lymphoblastoid human cell lines of various origins and proposed that the presence of the EB virus genome might be a general feature of all continuously growing human lymphoblastoid cell lines. These data have recently been confirmed by Nonoyama and Pagano (1971). 
In an extension of their work Zur Hausen, Schulte-Holthausen, Klein, Henle, Henle, Clifford, and Santesson (1970) examined 13 Burkitt lymphoma and 10 nasopharyngeal carcinoma biopsies and showed that they all contained EB viral DNA in one to 26 viral genome equivalents per cell. No EB viral DNA was found in biopsies of 10 other tumours even though all these control cases had EB virus antibodies and thus were presumably carriers of the virus. All these experiments showed that EB virus may act like well known oncogenic DNA viruses, persisting in a masked form as viral DNA in every tumour cell and every transformed continuously growing cultured cell and at the same time exerting specific genetic activity.

Thus, we see that the EB virus satisfies the first Henle postulate entirely. The EB viral genome and the viral-determined membrane antigen are present in all Burkitt lymphomas and derived cell lines while other viral-determined antigens like viral capsid and early antigens, complement-fixing, and the immunoprecipitation antigens are suppressed in vivo and only express themselves when the tumour cells are cultured; similarly the presence of formed virus particles is supressed in vivo but expressed in vitro.

\section{Transformation of Normal Cells by Virus in vitro}

The Henles in Philadelphia (Henle, Diehl, Kohn, Zur Hausen, and Henle, 1967) and Pope in Australia (Pope, Horne, and Scott, 1968) have shown that EB virus has the ability to confer the power of unlimited proliferation in culture on normal human peripheral lymphocytes. In other words, attempts to culture peripheral lymphocytes of EB virus-antibodynegative donors are regularly unsuccessful but if these lymphocytes are infected with $\mathrm{EB}$ virus in vitro they become carrier cultures and proliferate indefinitely in vitro and these established lines reveal the presence of EB virus-related antigens, namely, viral capsid, early, and membrane antigens. Even in the few cases where 'virus-free' lymphoblastoid cell lines have been established, with no evidence of EB virus by electron microscopy or immunofluorescence, the finding of EB viral DNA and the EB virusdetermined complement-fixing (S) antigen shows that the EB viral genome is present and exerting its transforming function.

These results fulfil several of the criteria established for transformation of normal cells by oncogenic animal viruses but, of course, in the case of the EB virus-transformed cells, we are denied the final proof of malignant transformation only obtainable by injecting the transformed cells into a suitable human host.
EB virus is also the aetiological agent of at least one form of infectious mononucleosis. Thus, the crucial significance of this virus lies in the fact that it is a stimulator of lymphoproliferation, not only capable of conferring the power of unlimited growth on normal human lymphocytes in vitro but also responsible for the lymphoproliferation of infectious mononucleosis in vivo. Thus, the $\mathrm{EB}$ virus can be said to satisfy most of the second Henle postulate.

3 Demonstration of Antibodies to Virus-related Antigens at Higher Frequency and/or Higher Titres in Patients with Given Malignancies than in Healthy Individuals or in Patients with Other Tumours

The Henles and the Kleins and their extensive work in this field over a number of years have amply demonstrated that EB virus satisfies this third postulate (Klein, 1972). One hundred per cent of African patients with Burkitt's lymphoma have antibodies to viral capsid antigen, usually at high titres. The geometric mean anti-EB virus titre of patients with Burkitt's lymphoma is eight times higher than in normal controls or control groups with other malignancies of the lymphoreticular system. As well, nearly all patients with Burkitt's lymphoma have antibodies to EB virus-determined membrane antigen and over $75 \%$ have antibodies to $\mathrm{EB}$ virusinduced early antigen. Cases of nasopharyngeal carcinoma from Africa, China, Sweden, France, and the United States show equally regular and high EB virus-associated serological reactivity in relation to all antigen systems investigated (membrane, viral capsid, and early antigens). This is all in striking contrast to control groups of carcinoma of the hypopharynx or oropharynx or nasopharyngeal tumours other than carcinoma-these were either EB virusantibody negative or EB virus-antibody positive at low titres.

It is convenient to mention at this point that high EB virus-antibody titres were also seen in the sarcomatous form of Hodgkin's disease while in the paragranuloma type the antibody pattern was normal (Johansson, Klein, Henle, and Henle, 1970).

4 Induction of Tumours in Non-human Primates or Other Animals by Inoculation of Virus

This last postulate has not been satisfied by EB virus and after eight years the search still continues for a suitable animal model, but under this heading we might conveniently examine some findings in the field of comparative lymphoma research which have added fresh pointers to the possible role of the herpestype EB virus in human neoplasia. There are now three herpes viruses that are known to be oncogenic 
for animals including a subhuman primate. Churchill and Biggs (1967) showed that a herpes virus (MDHV) was the cause of Marek's disease which is a very common, highly infectious lymphoid tumour of chickens, and more recently Japanese workers have claimed that MDHV shares a common antigen with EB virus (Ono, Tanable, Naito, Doi, and Kato 1970). Again, the herpes virus which causes the Lucké renal adenocarcinoma of leopard frogs (Mizell, Toplin, and Isaacs 1969) has been shown to share a common antigen with EB virus (Fink, King, and Mizell, 1968). And again, Herpes saimiri, which regularly induces a rapidly fatal reticulum cell sarcoma on inoculation into both owl monkeys and marmosets (Meléndez et al, 1969, 1970), has recently been shown capable of inducing acute lymphatic leukaemia in owl monkeys (Meléndez, Hunt, Daniel, Blake, and Garciá, 1971); incidentally it is worth remarking that $H$. saimiri thus represents the first DNA leukaemogenic agent.

We have seen that of the four Henle postulates which a suspected human tumour virus must satisfy before it can be termed definitely oncogenic in man, EB virus seems to satisfy three and the fourth is as yet unfulfilled because ethical considerations deprive us of the use of man as a biological model. Attempts have therefore to be made to cross species barriers and to induce tumours not in the natural host of EB virus, man, but in animals.

At this stage, it is worth considering the actual mechanism by which an oncogenic virus transforms a normal cell into a neoplastic one. In the case of DNA oncogenic viruses, the first requirement is the persistence of the viral nucleic acid within the transformed cell. In the case of the herpes DNA oncogenic viruses, a second requirement must be a non-productive infection since productive infection with herpes viruses is invariably a lytic infection. The third requirement is more controversial but many workers today think virus-induced membrane change is the key oncogenic parameter. Such membrane antigen changes are found in all experimental tumours and transformed cells. Regulation of cellular growth, whether hormonal or contactual, must be mediated via receptors on the cellular membrane and these receptors might be so changed in a non-lytic virus infection as to become insensitive to regulation, and, if this non-lytic infection is compatible with cellular division, a neoplastic cell might be the result. Here it would be appropriate to consider these membrane changes in relation to herpes viruses. Roizman (1971) found that in the case of herpes simplex (HSV) infection, viral envelope material was inserted into the cellular membrane and led to differences in social behaviour of the cell; he also found that infection with different herpes simplex virus mutants led to different types of social behaviour, each characteristic of the different mutant. These changes in social behaviour in the infected cells included clump forming of various sizes and adhesiveness, cell fusion, cell paralysis, adsorption of sensitized sheep erythrocytes, etc. Although these cells were lytically infected, it is not difficult to imagine a non-productive, non-lytic herpes virus infection changing the cellular membrane and hence the social behaviour of the cell towards lack of response to growth regulation while allowing the cell to grow and divide. The one provision here for an oncogenic herpes virus is that the membrane change must be early and independent of viral DNA synthesis and late viral functions which always lead to lysis. An experimental model of this last proposition has recently been described by Duff and Rapp (1971). They used HSV-2 inactivated by ultraviolet light in order to obtain a non-productive non-lytic infection and with this inactivated HSV-2 they transformed hamster cells in vitro, and these non-productive transformed cells not only contained HSV-specific antigens and induced tumours on reimplantation into hamsters but also bore new antigen on their membranes since virus-neutralizing antibodies appeared in the tumour-bearing hamsters.

The EB virus fits very well into the role of oncogenic virus as outlined above and even better into that of herpes DNA oncogenic virus. First we see that EB virus does indeed persist in the form of its nucleic acid within the transformed cell. Secondly, EB virus produces a persistent, latent, non-productive, nonlytic infection in the target cells and this is mirrored exactly by the MDHV and Herpes saimiri tumour systems. Thirdly, EB virus induces the production of membrane antigen which is an early antigen independent of viral DNA synthesis, and these membrane changes may conceivably alter the social behaviour of the cell towards disobedience to growth regulation and this, coupled with cellular viability, as EB virus is a non-lytic virus in the tumour situation, would result in a neoplastic cell.

Two further points of similarity between EB virus and oncogenic animal viruses might here be mentioned. First, EB virus is widely present in human populations and the induction of a tumour must be looked upon as a very unusual effect involving a rare individual out of the large numbers infected, in the same way as widespread murine and avian tumour viruses initiate neoplasia only in a small minority of infected animals. Secondly, Gerber (1971) reported that EB virus induces cellular DNA synthesis in infected lymphoid cells and, in this, EB virus resembles SV40 and polyoma. However, lymphoid cells can react to non-specific antigenic stimulation with DNA synthesis, but Gerber thinks that this 
explanation can be excluded since inactivated EB virus did not induce DNA synthesis.

\section{Role of EB Virus in Human Malignancies}

As far as EB virus and its role in human malignancies like Burkitt lymphoma and nasopharyngeal carcinoma are concerned, there are two possible hypotheses to be considered.

\section{THE PASSENGER HYPOTHESIS}

It has been suggested that perhaps EB virus is an opportunistic passenger in lymphoid tissue and that it replicates actively during any lymphoproliferative disorder. This seems extremely unlikely insofar as there is no regular high-titred EB virus association with lymphoproliferative diseases other than Burkitt's lymphoma and infectious mononucleosis such as acute lymphoblastic leukaemia, lymphosarcoma, or infectious lymphocytosis, nor with carcinomas of the head and neck other than nasopharyngeal, nor with nasopharyngeal tumours other than carcinoma. Also in Hodgkin's disease it is the lymphocyte-depleted sarcomatous form which shows high anti-EB virus activity while the lymphocyte-rich paragranulomatous form is low-reactive and resembles controls.

\section{CO-FACTOR HYPOTHESIS}

In animals there are many examples of tumour viruses which need one or more co-factors before being able to exert their oncogenic influence. One of the best documented is the development of mouse mammary carcinoma, which requires not only the presence of the mouse mammary tumour virus but also a certain inherited genetic constitution, and thirdly ovarian hormonal stimulation of the mammary gland.

Burkitt (1970) has persuasively argued that hyperendemic malaria may act as a co-factor with EB virus in the aetiology of Burkitt's lymphoma in those tropical regions where Burkitt's lymphoma is endemic. Both malaria and Burkitt's lymphoma appear to be limited by the same altitude, temperature, and rainfall barriers. There are only two areas in the world where malaria is holo-endemic, tropical Africa and New Guinea, and these are precisely the two areas where Burkitt's lymphoma is endemic; it is rare in tropical areas where malaria is not holo-endemic. There are many areas where malaria and Burkitt's lymphoma were common but since the eradication of malaria in these areas its incidence has also been reduced. Sickle cell trait is known to confer partial protection against falciparum malaria and children with this trait have only half the risk of developing Burkitt's lymphoma as do children with normal AA genotype (Williams,
1966; Pike, Morrow, Kisuule, and Mafigiri, 1970). Experimental evidence for the synergic action of a plasmodium and an oncogenic virus has been presented by Wedderburn (1970) who showed that concurrent infection with a murine plasmodium (Plasmodium berghei yoelli) increased the incidence of malignant lymphoma following the injection of Moloney virus into mice. Malaria is a powerful stimulator of reticuloendothelial proliferation and constant assaults on the reticuloendothelial systems of the populations in areas where malaria is hyperendemic might well provide an appropriate altered cellular soil which might be more susceptible to EB virus-induced malignant transformation.

In this hypothesis, environmental and genetic co-factors interacting with the EB virus would have to be considered in nasopharyngeal carcinoma, in view of the highly unusual epidemiology of this tumour.

To sum up, EB virus is widely present in human populations throughout the world. The most common result of infection with this virus is seroconversion without recognizable illness, exactly as occurs with poliomyelitis where only a tiny minority of people infected develop the paralytic disease. As a relatively rare event, particularly in late adolescence, primary infection with EB virus might lead to the limited and reversible lymphoproliferation of infectious mononucleosis. It is postulated that, in an extremely rare individual, infection might stimulate the unlimited proliferation of malignant lymphoma, the host response being dependent on many factors of which host immunological status and capacity would be among the most important. In those tropical regions where Burkitt's lymphoma is endemic, some climate-dependent co-factor, like hyperendemic malaria, would be superimposed on this pattern. In such a system it would of course be the hyperendemic malaria that would determine the climate dependence of the tumour.

In the immediate future there would seem to be two avenues of approach which would be important in giving a final answer to the question of the role EB virus plays in Burkitt's lymphoma. Burkitt's lymphoma has many features which make it an ideal neoplasm for aetiological investigations. Sixty per cent of all patients with Burkitt's lymphoma are between the ages of 4 and 8 years with an extremely pronounced peak at 5 years so that experimental observations need not run into decades. Burkitt's lymphoma is a highly antigenic tumour and therefore, by analogy with experimental animal tumours, probably has a short latency period since highly antigenic tumours are quickly rejected unless they grow rapidly enough to outpace the immune response. The first approach-a prospective sero- 
epidemiological study-should be rewarding. The second approach would be to follow the model of MDHV and MD which EB virus and Burkitt's lymphoma so closely mirrors. Churchill and his colleagues (1969) used a live attenuated MDHV to immunize chickens which were completely protected when challenged later with virulent virus. Now EB virus, like MDHV, is a horizontally transmitted agent and so should be amenable to classic vaccine approaches as soon as a safe and effective EB virus antigenic preparation is obtainable. Within five to 10 years the results of a clinical EB vaccine trial in Burkitt's lymphoma endemic areas could be determined.

\section{References}

Ahmed, M., Jensen, K. E., Slattery, S. M., Leech, J. B., and Schidlovsky, G. (1970). Detection of Marek's disease herpesvirus antigen by fluorescent and coating antibody. Avian Dis., 14, 349-363.

Burkitt, D. P. (1970). An alternative hypothesis to a vectored virus. In Burkitt's Lymphoma, edited by D. P. Burkitt and D. H. Wright, pp. 210-214. Livingstone, Edinburgh.

Churchill, A. E., and Biggs, P. M. (1967). Agent of Marek's disease in tissue culture. Nature (Lond.), 215, 528-530.

Churchill, A. E., Payne, L. N., and Chubb, R. C. (1969). Immunization against Marek's disease using a live attenuated virus. Nature (Lond.), 221, 744-747.

Duff, R., and Rapp, F. (1971). Oncogenic transformation of hamster cells after exposure to herpes simplex virus type 2. Nature [new Biol.], 233, 48-50.

Epstein, M. A., and Achong, B. G. (1970). The EB virus. In Burkitt's Lymphoma, edited by D. P. Burkitt and D. H. Wright, pp. 231-248. Livingstone, Edinburgh.

Epstein, M. A., Achong, B. G., and Barr, Y. M. (1964). Virus particles in cultured lymphoblasts from Burkitt's lymphoma. Lancet, 1, 702-703.

Fink, M. A., King, G. S., and Mizell, M. (1968). Preliminary note: identity of a herpesvirus antigen from Burkitt lymphoma of man and the Lucké adenocarcinoma of frogs. J. nat. Cancer Inst., 41, 1477-1478.

Gerber, P. (1971). In symposium on Oncogenesis and Herpes-Type Viruses, Cambridge, June 1971 (in press).

Henle, W. (1971). Evidence for a relation of the Epstein-Barr virus to Burkitt's lymphoma and nasopharyngeal carcinoma. In Recent Advances in Human Tumor Virology and Immunology. (Proceedings of the 1st International Symposium of the Princess Takamatsu Cancer Research Fund), edited by W. Nakahara, K. Nishioka, T. Hirayama, and Y. Ito, pp. 361-367. University of Tokyo Press, Tokyo.

Henle, W., Diehl, V., Kohn, G., Zur Hausen, H., and Henle, G. (1967). Herpes-type virus and chromosome marker in normal leukocytes after growth with irradiated Burkitt cells. Science, 157, 1064-1065.

Henle, G., and Henle, W. (1966). Immunofluorescence in cells derived from Burkitt's lymphoma. J. Bact., 91, 1248-1256.

Henle, W., Henle, G., Zajac, B., Pearson, G., Waubke, R., and Scriba, M. (1970). Differential reactivity of human serums with early antigens induced by Epstein-Barr virus. Science, 169, 188-190.

Johansson, B., Klein, G., Henle, W., and Henle, G. (1970). EpsteinBarr virus (EBV) - associated antibody patterns in malignant lymphoma and leukemia. 1. Hodgkin's disease. Int. J. Cancer, 6, 450-462.

Klein, G. (1972). Immunological aspects of Burkitt's lymphoma. In Advances in Immunology, edited by F. J. Dixon and $\mathbf{H}$. G. Kunkel, pp. 187-250. Academic Press, New York and London.

Klein, G., Clifford, P., Klein, E., and Stjernswärd, J. (1966). Search for tumor-specific immune reactions in Burkitt lymphoma patients by the membrane immunofluorescence reaction. Proc. nat. Acad. Sci. (Wash.), 55, 1628-1635.

Klein, G., Klein, E., and Clifford, P. (1967). Search for host defenses in Burkitt lymphoma: membrane immunofluorescence tests on biopsies and tissue culture lines. Cancer Res., 27, 2510-2520.

Meléndez, L. V., Daniel, M. D., Hunt, R. D., Fraser, C. E. O., Garciá, F. G., King, N. W., and Williamson, M. E. (1970). Herpesvirus saimiri. V. Further evidence to consider this virus as the etiological agent of a lethal disease in primates which resembles a malignant lymphoma. $J$. nat. Cancer Inst., 44, 1175-1181.

Meléndez, L. V., Hunt, R. D., Daniel, M. D., Blake, B. J., and Garciá, F. G. (1971). Acute lymphocytic leukemia in owl monkeys inoculated with Herpesvirus saimiri. Science, 171, 1161-1163.

Meléndez, L. V., Hunt, R. D., Daniel, M. D., Garciá, F. G., and Fraser, C. E. O. (1969). Herpesvirus saimiri. II. An experimentally induced primate disease resembling reticulum cell sarcoma. Lab. Animal Care, 19, 378-386.

Mizell, M., Toplin, I., and Isaacs, J. J. (1969). Tumor induction in developing frog kidneys by a zonal centrifuge purified fraction of the frog herpes-type virus. Science, 165, 1134-1137.

Nadkarni, J. S., Nadkarni, J. J., Klein, G., Henle, W., Henle, G., and Clifford, P. (1970). EB viral antigens in Burkitt tumour biopsies and early cultures. Int. J. Cancer, 6, 10-17.

Nonoyama, M., and Pagano, J. S. (1971). Detection of Epstein-Barr viral genome in nonproductive cells. Nature [new Biol.], 233, 103-106.

Old, L. J., Boyse, E. A., Oettgen, H. F., de Harven, E., Geering, G., Williamson, B., and Clifford, P. (1966). Precipitating antibody in human serum to an antigen present in cultured Burkitt's lymphoma cells. Proc. nat. Acad. Sci. (Wash.), 56, 1699-1704.

Ono, K., Tanabe, S., Naito, M., Doi, T., and Kato, S. (1970). Antigen common to a herpes type virus from chickens with Marek's disease and EB virus from Burkitt's lymphoma cells. Biken J., 13, 213-217.

Pike, M. C., Morrow, R. H., Kisuule, A., and Mafigiri, J. (1970). Burkitt's lymphoma and sickle cell trait. Brit. J. prev. soc. Med., 24, 39-41.

Pope, J. H., Horne, M. K., and Scott, W. (1968). Transformation of foetal human leukocytes in vitro by filtrates of a human leukaemic cell line containing herpes-like virus. Int. J. Cancer, 3, 857-866.

Pope, J. H., Horne, M. K., and Wetters, E. J. (1969). Significance of a complement-fixing antigen associated with herpes-like virus and detected in the Raji cell line. Nature (Lond.), 222, 186-187.

Rabson, A. S., O'Conor, G. T, Lorenz, D. E., Kirschstein, R. L., Legallais, F. Y., and Tralka, T. S. (1971). Lymphoid cell-culture line derived from lymph node of marmoset infected with Herpesvirus saimiri: preliminary report. .I. nat. Cancer Inst., 46, $1099-1109$.

Roizman, B. (1971). In symposium on Oncogenesis and Herpes-Type Viruses, Cambridge, June 1971 (in press).

Walters, M. K., and Pope, J. H. (1971). Studies of the EB virusrelated antigens of human leukocyte cell lines. Int. J. Cancer, 8 , $32-40$.

Wedderburn, N. (1970). Effect of concurrent malarial infection on development of virus-induced lymphoma in $\mathrm{Balb} / \mathrm{c}$ mice. Lancet, 2, 1114-1116.

Williams, A. O. (1966). Haemoglobin genotypes, ABO blood groups, and Burkitt's tumour. J. med. Genet., 3, 177-179.

Zajac, B. A., and Kohn, G. (1970). Epstein-Barr virus antigens, marker chromosome, and interferon production in clones derived from cultured Burkitt tumor cells. J. nat. Cancer Inst., 45, 399-406.

Zur Hausen, H., and Schulte-Holthausen, H. (1970). Presence of EB virus nucleic acid homology in a 'virus-free' line of Burkitt tumour cells. Nature (Lond.), 227, 245-248.

Zur Hausen, H., and Schulte-Holthausen, H. (1971). In symposium on Oncogenesis and Herpes-Type Viruses, Cambridge, June 1971 (in press).

Zur Hausen, H., Schulte-Holthausen, H., Klein, G., Henle, W. Henle, G., Clifford, P., and Santesson. L. (1970). EBV DNA in biopsies of Burkitt tumours and anaplastic carcinomas of the nasopharynx. Nature (Lond.), 228, 1056-1058. 